\title{
MIMOSA MARTINDELCAMPOI MEDRANO (LEGUMINOSAE), UNA ESPECIE NUEVA DEL SUDOESTE DE TAMAULIPAS, MEXICO.*
}

\author{
FRANCISCO GONZALEZ MEDRANO**
}

\section{RESUMEN}

Mimosa martindelcampoi (Leguminosae) se describe como nueva especie procedente del sudoeste de Tamaulipas. Esta especie está cercanamente relacionada con Mimosa leucaenoides Benth., pero el número de estambres y folíolos es diferente, $M$. leucaenoides tiene 8 estambres y la nueva especie tiene 10. Actualmente la nueva especie solo se conoce del sudoeste de Tamaulipas.

\section{ABSTRACT}

Mimosa martindelcampoi (Leguminosae) a new species from southwestern Tamaulipas is described. This species is most closely related to Mimosa leucaenoides Benth., but the number of stamens and leaflets is different, $M$. leucanoides has 8 stamens and the new species 10 . This plant is known at present only from southwestern Tamaulipas.

El género Mimosa L. se encuentra ampliamente representado en México, con más de 100 especies reconocidas. Basados en el número de estambres por flor, el género puede dividirse en dos secciones:

Con las flores con el doble número de estambres que pétalos, la sección Habbasia D.C. (Sectio Bataucaulo D.C.; Sectio Ameria Benth.), y la Sección Mimosa (Sectio Eumimosa D.C.), cuyas especies poseen flores con el mismo número de estambres que pétalos (generalmente cuatro).

En los matorrales calcícolas de la zona árida del Sudoeste de Tamaulipas recolecté una Mimosa la cual, después de analizarla con cuidado, consideré que se trataba de una especie nueva, la cual describo a continuación:

* Trabajo aceptado para su publicación en agosto de 1982.

** Instituto de Biología, UNAM, y UAM Iztapalapa. 


\section{BOLETIN DE LA SOCIEDAD BOTANICA DE MEXICO No. 43, 1982}

\section{Mimosa martindelcampoi, sp. nov.}

Frutex profuse ramosus usque ad $2 \mathrm{~m}$ altus. Caulis pardus ad rubens, inermis. Folia 7-9.5 cm longae; petioli 0.9-2.1 cm longi; foliola duo paria per pinnam, glabra, reniformia, versus basim obliqua, $1.8-3 \mathrm{~cm}$ longa, $2-3 \mathrm{~cm}$ lata, margine crenato aut paululum undulato, venatione elevata et flavescenti utroque facie, tergo praesertim. Stipulae subulatae $3 \mathrm{~mm}$ longae, $0.8 \mathrm{~mm}$ latae. Flores in capitulum ovoideum aggregati, capitula 1-2 $\mathrm{cm}_{4}$ diametro, pedunculatae, $3-5$ in fasciculis axillaribus, ebracteatis, pedunculus $2-4 \mathrm{~cm}$ longus; flores sessiles purpureo ad violaceum; calyx $1 \mathrm{~mm}$ longus lobulis apice acutis, ciliatis; corolla radiata, tubularis, petalis $3 \mathrm{~mm}$ longis, $1 \mathrm{~mm}$ latis in portione media, apice mucronulato; stamines $10,6-8 \mathrm{~mm}$ longae, exsertae, antherae $5 \mathrm{~mm}$ longae, dorsifixae, introrsae; ovarius glabrus $1 \mathrm{~mm}$ longus, sessilis; stylus filiformis $6 \mathrm{~mm}$ longus, ovulis 3-5. Fructus pedicellatus, oblongus ad linearem, $1.4-1.6 \mathrm{~cm}$ latus, $3.5-7 \mathrm{~cm}$ longus, mucrone $2-5 \mathrm{~mm}$ longo, plerumque complanatus, rectus aut curvatus, membranosus, indehiscens, bivalvus, valvae a marginibus persistentibus separantur, in transverse segmentis uniseminatis divisus. Semina glabra, compressa, late ovata 5.5-5.7 mm.

Arbusto hasta de $2 \mathrm{~m}$. de alto, de tallo glabro, aunque las ramillas esparcidamente pilosas, profusamente ramificado, con abundantes lenticelas acomodadas sobre estriaciones longitudinales poco aparentes; el tallo color pardo a rojizo.

Hojas bipinnadas, alternas de 7 a $9.5 \mathrm{~cm}$ de largo, con pecíolos de 0.9 a $2.1 \mathrm{~cm}$ de largo, con dos pares de folíolos por pinna, éstos glabros, reniformes, oblicuos hacia la base, de $1.8 \mathrm{~cm}$ a $3 \mathrm{~cm}$ de largo, de 2 a $3 \mathrm{~cm}$ de ancho, con los bordes crenados 0 ligeramente ondulados, de venación muy prominente en ambas caras y flavescente principalmente en el envés; estípulas subuladas de $3 \mathrm{~mm}$ de largo por $0.8 \mathrm{~mm}$ de ancho.

Flores en cabezuelas ovoides, globosas, pedunculadas, en fascículos axilares de 3 a 5 pedúnculos, ebracteados, cada pedúnculo de 2 a $4 \mathrm{~cm}$ de largo, las cabezuelas de 1 a $2 \mathrm{~cm}$ de diámetro. Flores sésiles, púrpuras a violáceas, cáliz de $1 \mathrm{~mm}$ de largo, con los lóbulos con el ápice agudo, ciliados; corola gamopétala, radiada, tubular, pétalos de $3 \mathrm{~mm}$ de largo por $1 \mathrm{~mm}$ de ancho en la porción media, con el ápice mucronulado.

Estambres 10, de 6 a $8 \mathrm{~mm}$ de largo, exertos, anteras de $5 \mathrm{~mm}$ de largo, dorsifijas, introrsas. (Figura)

Ovario glabro de $1 \mathrm{~mm}$ de largo, sésil, estilo filiforme de $6 \mathrm{~mm}$ de largo, con pocos (3-5) óvulos.

Fruto pedicelado, oblongo a linear, de 1.4 a $1.6 \mathrm{~cm}$ de ancho por 3.5 a $7.0 \mathrm{~cm}$ de largo, con un mucrón de 2 a $5 \mathrm{~mm}$ de largo. Comúnmente plano comprimido, recto a curvado.

Membranoso, indehiscente, con dos valvas, que se separan de los márgenes persistentes, dividido transversalmente en segmentos con una semilla.

Semillas glabras, comprimidas, anchamente ovadas, de 5.7 a $5.5 \mathrm{~mm}$.

Tipo: México: Tamaulipas. $7 \mathrm{Km}$ al norte de Magdaleno Aguilar (Santiaguillo). Municipio de Jaumave. Laderas calizas orientadas al sur a 1850 m.s.n.m., en matorral de crasirrosulifolios espinosos. Asociada a Nolina, Agave, Dasylirion, Yucca y Acacia. 14 de septiembre de 1976.

Col. F. González-Medrano, 9818, A. Castellanos V. y. P. Zavaleta B. Holotipo, MEXU; Isotipos (ENCB; K; TEX; MICH.; MO). 

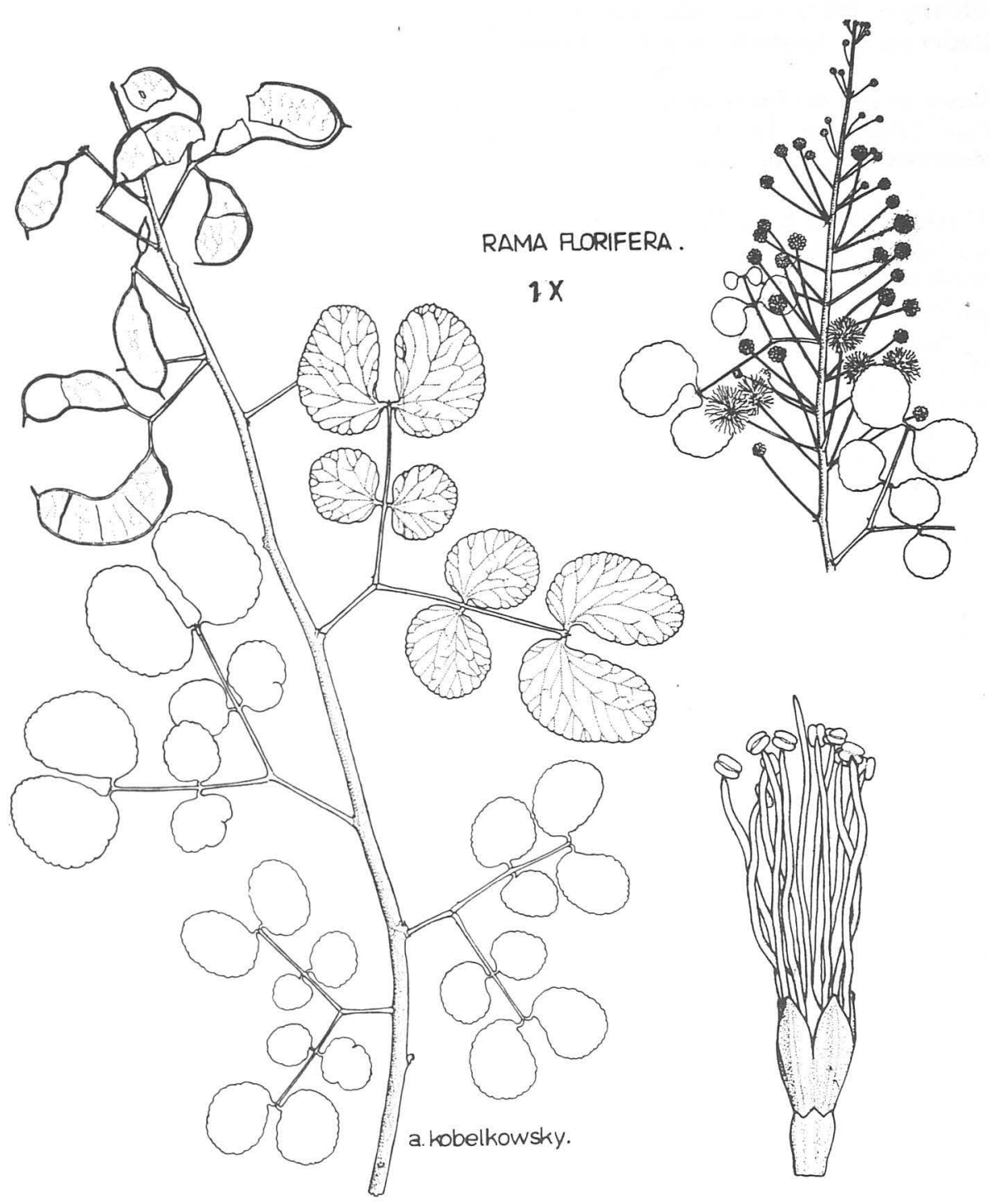

RAMA FRUCTIFERA. $1 X$

FLOR $28 x$

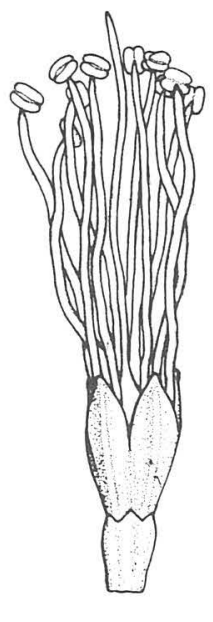


Otros ejemplares examinados:

$3 \mathrm{Kms}$ al nordeste de la Florida, Municipio de Jaumave. Tamaulipas, en matorral alto subinerme, ladera caliza orientada al norte. 19 de septiembre 1976. Col. F. González Medrano, A. Castellanos y P. Zavaleta No. 9854.

Cerros al este del Ejido coronel Ricardo García a $26 \mathrm{Kms}$ al norte de Tula. Municipio Tula. Tamaulipas. En matorral alto subinerme. 11 diciembre 1976. Col. F. González Medrano y F. Guevara Fefer. No. 10,206.

Al revisar el Herbario Nacional de México (MEXU) encontramos una planta similar, recolectada también en la parte sudoeste de Tamaulipas por Stanford, Retherford y Northcraft, 852, en agosto de 1941; dicho material consta de una ramilla con hojas, pedúnculos y unos cinco o seis capítulos. Según la etiqueta de herbario es un isotipo de Acacia trium especie nueva de I.M. Johnston; analizando las flores, éstas correspondieron a una Mimosa, similar a la planta encontrada por nosotros; Johnston no publicó el taxón referido, por tanto no creó ninguna prioridad.

Las relaciones de parentesco de la especie descrita no parecen ser muy claras; dentro de las especies inermes del género y con las hojas algo coriáceas, parece tener relaciones con Mimosa leucaenoides Benth. Difiriendo de ésta por el menor número de folíolos por pinna y por la forma y tamaño de éstos, siendo reniformes en la nueva planta y obovados a subrómbicos en $M$. leucaenoides Benth., además de que $M$. leucaenoides posee 8 estambres y la especie nueva tiene 10 .

En la localidad tipo de Mimosa martindelcampoi, ambas especies conviven formando parte de los matorrales xerófilos en los suelos pedregosos derivados de calizas. La especie vegetativamente se confunde con Acacia crassifolia Gray, arbusto con el cual es frecuente en algunas localidades, salvo por las espinas de esta última.

Esta especie hasta ahora conocida del sudoeste de Tamaulipas, se suma al grupo de taxa restringido a esta región o con algunas extensiones un tanto más al sur hacia la zona árida del estado de Querétaro, como Savia neurocarpa, Bonetiella anomala, Hesperaloe funifera, Mirandaea grisea, y otras.

La especie está dedicada al M. en C. Rafael Martín del Campo, del Instituto de Biología, por su apoyo y ayuda para la formación de jóvenes biólogos.

\section{AGRADECIMIENTOS}

Agradezco al licenciado Javier Palencia la diagnosis latina; al biólogo A. Kobelkowski el dibujo que acompaña la descripción; al Doctor Fernando Chiang, su revisión crítica del original y de la versión latina. 